\title{
The other H-index: the hyperbole index
}

\author{
David Cann ${ }^{1, *}$ \\ ${ }^{1}$ Materials Science, School of Mechanical, Industrial and Manufacturing Engineering, Oregon State University, 204 Rogers Hall, \\ Corvallis, OR 97331, USA
}

Received: 29 May 2019

Accepted: 29 May 2019

Published online:

7 June 2019

(C) Springer Science+Business

Media, LLC, part of Springer

Nature 2019

This invited viewpoint co-authored by Dr. Andrew J. Bell and Dr. Dragan Damjanovic, both preeminent researchers in electroceramics, elaborates on the unintended but not inconsequential impact of the use of hyperbole in scientific communication with a focus on recent research on the development of lead-free piezoelectric materials. In writing a manuscript for a peer review journal such as the Journal of Materials Science, it is of course customary to justify the basic purpose of the research. This is absolutely critical when writing grant proposals, but within scientific communications, it is also helpful to provide the proper context for the results in relation to some technological target (e.g., properties, functionality, cost, etc.). While as a scientific community, we (i.e., researchers, editors, technology developers and end users) all share a common fundamental understanding of the need to present the research findings with the utmost honesty and integrity (and by "findings" I mean the actual data). These ideals are not uniformly adhered to in describing the impact of those findings, and this is where hyperbole fills the void as a means of enhancing the impact of the work.

This invited viewpoint examines ongoing research on lead-free piezoelectric ceramics as one example, which the authors are intimately familiar with, but there are many others. Looking back on my own publications, I am guilty of similar exaggerations and mischaracterizations. With the explosion of display technologies in the late 1990s and early 2000s, many authors (myself included) would justify work on new materials that could replace indium tin oxide (ITO) on the basis of worldwide concerns over the supply of indium. While technically it was true that there was a concern; however, that concern was unfounded according to published economic geologic resource surveys [1]. The exemplar case in this invited viewpoint, the development of lead-free piezoelectric materials, considers the fundamental motivations of that large body of work expressed by authors in light of the true environmental and societal impact of replacing lead-based piezoelectric materials with

Address correspondence to E-mail: cann@oregonstate.edu 
lead-free materials. The timing of this discussion is critically important, as the current policy exemption allowing the use of lead is up for review in 2020. As the following viewpoint explains, while misleading statements may seem innocuous, there are unintended consequences of the use of unfounded justifications expressed as hyperbolic statements of fact. Throughout the peer review process, we must recognize that we are communicating to a broad audience and while, as researchers, we are dedicated to representing the data in an ethical manner, we must be just as vigilant in all other parts of the manuscript (not just the justification, but the experimental section, declaration of conflicts of interest, references, etc.). Otherwise, misleading statements and hyperbole may metastasize with detrimental effects on policy makers, researchers and technology end users. Ultimately, this may reduce trust in science and scientists at a time when the integrity of the scientific process is challenged regularly.

\section{References}

[1] Schwartz-Schampera U, Herzig PM (2002) Indium: geology, mineralogy and economics. Springer, Berlin

Publisher's Note Springer Nature remains neutral with regard to jurisdictional claims in published maps and institutional affiliations. 